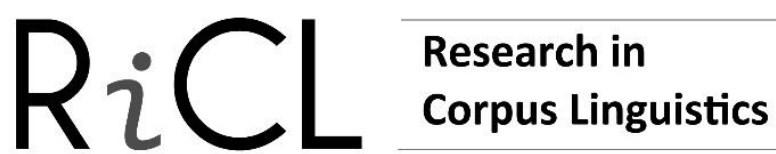

\section{Review of Hickey, Raymond and Carolina P. Amador-Moreno eds. 2020. Irish Identities: Sociolinguistic Perspectives. Berlin: Mouton de Gruyter. ISBN: 978-1-501-51610-8. https://doi.org/10.1515/9781501507687}

\author{
Fiona Farr \\ University of Limerick / Ireland
}

At the end of running the large international CL2021 conference online, I am reading and reviewing this edited collection at leisure. This is the way a book should be read, but so often is not. I have no specific utilitarian need to read it to inform any pressing research or writing of my own. Nor am I using it to update teaching or reading materials immediately in advance of a new semester. Although, in time, it is sure to support all of these academic endeavours. Instead, I am reading it for personal interest and professional curiosity, being an Irish-English speaker and an applied linguist. And I have enjoyed reading every page and every chapter it contains. It has taken me on a broader linguistic journey than I had anticipated and has piqued my interest at every more and less familiar methodological corner. It is unusual and very refreshing to find such an offering of traditions, approaches, contexts, and even languages represented in one volume, but more of that later.

This edited collection explores issues which affect the relationship between language and society in Ireland. It emanates from a special topic panel at the Sociolinguistics Symposium in Murcia in 2016. More specifically, the volume focuses on how identity is signalled through the use of English in Ireland, with inevitable strong reference to the Irish language also. On a macro-level the book divides into two parts. Part I, containing seven chapters, deals with historical and contemporary dimensions of identity. Part II, with its six chapters, explores linguistic identity across diverse sources. So, essentially the first part provides a broad historical and linguistic context for the more genre-based investigations in the second.

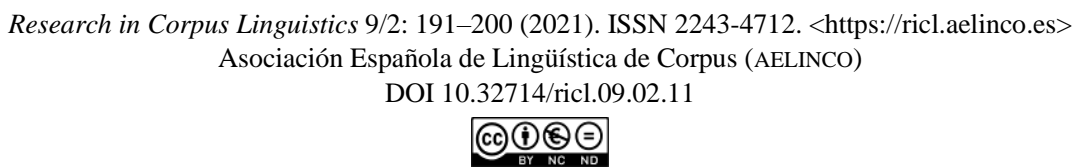


The opening chapter of Part I, authored by the book's editors Hickey and AmadorMoreno, introduces the main contexts and issues which are addressed in later chapters. It begins by attempting the impossible and offering a definition of identity as something individual yet collective, fixed yet variable. Social factors which impact identity including age, gender, social status, socio-economic class, and ethnicity are introduced as variables which frame some of the later discussions in the volume. The editors rightly claim that this book fills a gap in the literature as among the many research volumes on identity within the broad field of sociolinguistics (and I would add also the general field of applied linguistics), none before now have been devoted to the context of language in Ireland (both the English and Irish languages). Different types of potentially overlapping identity are outlined, including national, regional, ethnic, group, cultural, class, religious, and personal, illustrated in many cases with examples of associated phonological features, most notably vowel sounds. As the authors acknowledge, there could be other types of identity also. One which struck me as I read was professional identity, although I suspect the authors see this as merging with others such as group, class and personal identities. The chapter finishes with an account of language identity and language shift and an illustration of how identity survived the shift from Irish to English in the eighteenth and nineteenth centuries, and a second significant linguistic shift before and after Irish independence from Britain in 1922. Overall, this first chapter provides an appropriate appetiser for the next chapter on the Irish language.

In Chapter 2, Walsh begins with a demography of the Irish language before drawing on a theoretical framework of language and ethnic-based identity from critical sociolinguistic studies. He explores statistical research on attitudes towards the Irish language gathered as part of national surveys between 1973 and 2013. This highlights interesting links between attitudes, identity, and political and economic trends at different points in time, for example, a display of more positive attitudes in times of recession, and negative in times of economic prosperity. The last part of the chapter reports on a very interesting project investigating attitudes of 'new speakers' of Irish, that is, fluent and regular speakers of Irish who have not been raised in a Gaeltacht area speaking Irish as a primary language. These are the kind of speakers my 84-year-old first language Irish speaking mother-in-law, born and raised in the Connemara Gaeltacht, would fondly refer to as 'book-Irish speakers', with an endearing appreciation that they 'do their best'. Walsh reports on 100 interviews with these new speakers and highlights here the themes related 
to language ideology and identity. Two main findings emerge. Firstly, identity is a motivator for becoming a new speaker of Irish. This operates in different ways for different groups. It seems that cultural nationalism is still found among some of the older speakers and understandably from Northern Ireland due to the complex political and religious history of that part of the island. Also, identity associated with the role of the Gaeltacht as a motivating factor, either through direct experiences or through familial links with parents or grandparents who come from those parts of the country. Secondly, the data show that identity positions of the new speakers vary on a cline from identifying as primarily Irish speakers, to having a mixed linguistic identity, to a small proportion who primarily identify as English speakers. These speakers are of course crucial to the sustained use of the Irish language in a context where native speakers of Irish continue to decline from already low numbers. The nuanced understandings resulting from this type of research are so important for the future of the language.

Mac Mathúna takes the reader on a journey of exploration in his historical narrative of identity, ideology and bilingualism in Ireland in Chapter 3. I was transported back to my secondary school history classes in the early 1980s with Miss Ring proudly animating the history of Ireland in a way that led us to believe it was the only country of significance on this planet. This chapter provides a relatively detailed extended history and rationale for the shift from Irish to English with an exploration of the complexities of why Irish did not remain the language of choice for domestic, social and cultural reasons while English was adopted for administration and commerce. One cited reason was the lack of a multiplication of manuscripts in Irish apart from some religious books and translations until the 1600s. A 300-year period, from 1600 to 1900, witnessed a sustained period of codemixing in the written language with the use of English playing an ancillary role to Irish. Interestingly, 1732 saw an Irish-English dictionary published in Paris. The chapter includes some illustrative examples of critical accounts of the use of English in legal arenas, especially in relation to land ownership and seizures. These were often found in mixed-code poetry of the time, beginning with the Warrant genre. The author concludes that calls in favour of the Irish language were all but lost at the end of this period and "religion, land, famine and emigration, and Home Rule were the great social and political issues of the $19^{\text {th }}$ century. Language had to wait in the wings" (p. 65).

A more linguistically detailed historical description of twentieth-century shifts in Irish English pronunciation follows in Chapter 4 by Hickey. This, he discusses from a 
'supraregional Irish English' perspective rather than on specific local varieties, although there is some reference in the chapter to Dublin English. Three significant periods are outlined for Irish English accent changes from the end of the nineteenth century to later in the twentieth century, coinciding with political changes and the independence of the south of Ireland from Britain in 1922. Some of these changes are illustrated through contrasting the speech of two public figures in Irish politics: W. T. Cosgrave (18801965), Prime Minister from 1922 to 1932, and his son, Liam C. Cosgrave (1920-2017), Taoiseach (Irish word for Prime Minister) from 1973-1977. Looking to the first period under scrutiny, Hickey claims that the accent of Irish English public figures born before 1900 sounds very much British. This is perhaps unsurprising given what we read in Chapter 4 about the gradual shift to English language under English rule over a sustained period. The most distinguishing Irish-English features at the time, however, were THstopping, T-frication, a GOAT-monophthong, a FOR/FOUR distinction and a WHAT/WATT distinction. The early twentieth century, a period of revolution preindependence, saw the following features emerge: rhoticity, a change in the STRUT, TRAP, PRICE and MOUTH vowels, HAPPY tensing, and a velarisation of syllable-final laterals. Post 1922 independence saw an endonormative reorientation, illustrated with a contrast of local Dublin English and supraregional Irish English, along with a brief account of Ulster English, which has had its own unique developmental path.

In Chapter 5, Schulte provides a further account of /t/ realisations in Dublin English, one of which manifests as an apico-alveolar fricative, which is rare cross-linguistically, and has been associated with stance-taking. The data for her study comes from interviews with seven young female Dubliners, aged 19-33, conducted between 2015 and 2017. She contrasts / $\mathrm{t} /$ pronunciation in two different speaking styles: reading and natural conversation. A range of different realisations are found in the reading data, and she concludes that a dropped word-final / $\mathrm{t} /$ seems to be associated with an unprestigious accent, and a fricated pronunciation with more prestige, as illustrated in this careful and monitored context. The conversational data (again from well-educated women) shows quite different patterns and a wider range of realisations that have been found among male working-class speakers in previous studies. Phonetic context and syntactic position were found to be influential, as well as speakers' identity and evaluative stances.

Chapter 6 investigates linguistic identity perceptions from a dialectal perspective. Lucek and Garnett aim to discover how Irish people perceive dialects of English in 
Ireland, by building on the work emanating from A Survey of Irish English Usage (Hickey 2004, 2007). The data for their study consists of the task-based responses of 23 adults who were asked to do the following on a completely blank map of Ireland: mark where they are from; draw boundaries around where they think dialects occur in Ireland and label the associated accents; describe the features of the accents and the characteristics of the people who use those dialects. The results presented in this chapter show that three dialects are clearly identified: Dublin, Cork and Northern Ireland. In the case of Dublin, further sub-divisions between North Dublin, Inner City, and South Dublin (D4) are discernible to many of the respondents, with more negative characteristics associated with the first two by some participants. The use of boy and the tag like were pinpointed as being associated with a Cork dialect, while specific aspects of Northern Irish English phonology are mentioned. Clear traces of 'otherness' surface in all cases and are deemed to be self-imposed, for example, in the case of people from Cork (one which I can clearly identify with as a Cork woman now living in exile in Tipperary). This perceived uniqueness and superiority is something that Cork people tend to wear with pride and carry with them. This is noticeable in slogans such as 'The People's Republic of Cork', emblazoned on a t-shirt recently gifted to my teenage daughter by her Cork cousins.

The final chapter in Part I of this volume explores Ulster Scots identity in today's Northern Ireland, that variety first brought there by settlers from Scotland in the seventeenth and eighteenth centuries. The chapter begins by highlighting the debates and divided opinion about the status of Ulster Scots as a language, a dialect of Scots or English, or something else entirely, something related to its ideological undercurrents and associations with Unionism and Protestantism. The following exploration draws on the written representation of Ulster Scots between 1750 and 1920, and at present (19952014), with a specific focus on spelling. The present-day data comes from the Miscellaneous Ulster-Scots Texts - Corpus (MUST-C), a work in progress consisting mainly of internet texts. Historical data comprise 28 literary works, while a set of lexicographical materials in the form of professional glossaries and word-collections from 1880 to 2012 are also used. Wolf uses corpus-based methods to analyse MUST-C, and employs more manual close-reading for the historical and lexicographical data, which are not available in digital format. This analysis led to the identification of a number of spelling variants, some shared with Scots in Scotland (for example, simplification of consonant cluster in final position), some independent Ulster-Scots features (for example, 
short central vowels in words such as Brätain, and some exclusive features compared with Mid-Ulster English (for example, half-open back vowel in LOT coarnmill). When comparing the historical variants with the more conventional data, more features are present, that is, increasing feature density. Present-day representations in MUST-C seem to want to display as much Ulster Scots spelling as possible, always a realisation of spoken forms. In addition, such texts have specific ideological associations with Loyalism and Unionism.

Clancy's Chapter 8 opens the series of chapters in Part II of the book, all dealing with identity across diverse sources. In it, he examines the personal pronouns he, she and $w e$ in intimate spoken data between couples, families and friends found in the 600,000word Limerick Corpus of Intimate Talk (LINT; see Clancy 2016). The corpus-based methodology he employs utilises word frequency lists, cluster and concordance analyses to investigate indexicality and identity through a pragmatics lens. We first see demonstrated the higher frequency of he and she in LINT relative to the British National Corpus $^{1}$ (Spoken BNC 2014; cf. Love et al. 2017) spoken, as the springboard for a more detailed analysis which reveals the high frequency two-word clusters is s/he, and $\mathrm{did} s / \mathrm{he}$, illustrated as question tags in the interesting discourse extracts provided. These, he suggests, are performing important pragmatic functions, such as co-construction in this type of intimate discourse, and may be indexes of Irish intimate identity. The second focus for analysis is the multi-functional pronoun we, this time illustrating a pronoun which occurs relatively less frequently in LINT. However, when it is used, it illustrates in-group and out-group identities between family members and friends. The author concludes by modestly acknowledging that the study is limited to examining only one form of indexicality as a marker of identity, amid a range of other possibilities. However, this corpus-based pragmatic exploration is meaningful also in other ways, especially in its examination of difficult-to-secure spoken intimate discourse.

Another corpus-based study is reported by Walshe in Chapter 9, this time with an intrinsically interesting focus on identity in the genre of Irish jokes. The corpus comprises 40 Irish joke books published worldwide (half international, that is British or North American publication origins, and half Irish) over the last 50 years, and is planned to build further to include more historical texts. Only jokes containing direct speech were included in this study, as the aim is to examine the representation of identity in Irish

\footnotetext{
${ }^{1}$ http://corpora.lancs.ac.uk/bnc2014
} 
speech as a fictional construct. In total, nine linguistic features indexing Irishness are examined, which show similar trends and frequencies across the datasets. The most frequent item in the North American, Great Britain and Irish (general and regional) subcorpora is the use of $m e$ for $m y$, for example, me hat. The other items include: the pragmatic marker sure; -in' for -ing; ye for plural you; redundant indeed, the lack of do support in questions (for example, Have you a driving licence?); religious expressions and euphemisms; non-standard use of the definite article (for example, the brother, the wife, the drink); and lack of subject-verb agreement (for example, I knows). Walshe concludes that there is a high degree of consistency in the way in which jokes published in Ireland and abroad represent Irish linguistic identity, but with some notable differences. Those published abroad were more likely to indicate an Irish accent, and also included more examples of $h$-dropping and intrusive $r$. And, interestingly, Irish speech is represented more in the American publications that their British counterparts (38\% vs. $26 \%)$.

Continuing in a similar vein, Vaughan and Moriarty explore the role that humorous texts play in the formation and perception of Irish identities (Chapter 10). A series of seven short, animated cartoons, Martin's Life, form the reference data for this particular study, along with audience responses in the form of YouTube comments. Both authors are well-accomplished in the scrutiny of similar genres in both Irish and Irish-English contexts from sociolinguistic perspectives and bring their expertise to bear again in the present chapter. They provide a detailed contextual account of these cartoons which depict the life of a recently returned emigrant to Cork (based on the accent, more West Cork) who finds himself back living with, and having to tolerate his stereotypical parents, whose traits and language create the humour upon which the series depends. The discussion in the chapter identifies a number of vernacular speech features, such as shur and $a u l$ before showing how these index local identities in such characterisations as the devoted but overbearing Irish Mammy figure and the non-politically correct Daddy figure. The final part of the analysis explores the YouTube commentaries (all positive) posted by the audience, those who ultimately authorise "the relevance of these animations" (p. 211). Several comments which evaluate the cartoons as authentic and familiar are highlighted, sometimes followed by an uptake of the stylised Cork Irish English features, for example, Ah shtop lads. The importance of such data to uncover Irish identity is discussed towards the end of this enlightening and amusing chapter. The 
only gripe I have with this chapter is that it took me much longer to read than planned, because, as a West Corkonian, I kept going back to watch the cartoons again. In them I heard familiar echoes of voices from my past and present, all of which made me laugh anew - my ultimate litmus test for the authentication of identity representation.

The role of radio advertising in identity construction is pursued by O'Sullivan in Chapter 11, particularly in relation to the use of different varieties of the same language, in this case, English in Ireland and Standard Southern British English (SSBE). It uses the Irish Radio Advertisement Corpus (IRAC; see O'Sullivan 2019), a corpus of 200 advertisements collected at five time-points between 1997 and 2017 to explore this concept in more detail. The linguistic exponent under scrutiny is the pronunciation of final $/ r /$ and whether it is retained or deleted. O'Sullivan successfully shows that there is change over time, with SSBE dominating as an 'outgroup form' in the 1977 and 1987 subcorpora. This decreases in the later corpora and is replaced by an advanced Dublin English supraregional accent, which is found in the 1997, 2007, and 2017 subcorpora, among speakers of different ages as time progressed. This is more clearly identifiable as Irish English. Moving to another genre produced for public consumption, Terrazas-Calero explores the Corpus of Fictionalised Irish English (CoFIrE) in Chapter 12. This corpus of sixteen works of fiction by eight Irish writers (see p. 278) is tagged for distinctive dialectal features. After an initial social-class indexed examination of Irish English use in the corpus, the author moves to a more linguistic analysis. This leads her to a focus on three recurrent pragmatic items: quotatives (go, be like, be there, etc); the taboo word fuck; and the discourse marker like. She examines these items linguistically while also indexing for sociolinguistic variables such as age, gender and emotional marking. Some of the interesting findings include the fact that fuck is used much more frequently by males in their twenties and thirties than any other age group found in the fictional data, plus the fact that the discourse marker like occurs 86 percent in clause-medial position. She ends on what I consider to be a very pertinent cautionary call that more investigation into the globalisation of Irish English is needed as this phenomenon may be a threat to Irish-English identity.

The final chapter of the book ends with one of the editing authors who also penned the first chapter. Amador-Moreno joins with Ávila-Ledesma to take us back in time once again to explore some of the ways in which identity is marked in nineteenth-century Irish emigrant letters represented in the Corpus of Irish English Correspondence (CORIECOR; 
McCafferty and Amador-Moreno in preparation). Specifically, they use a subcorpus from Argentina and another from the USA to investigate the ways in which the words home, here, and there help in the construction of identity. There was a connection with the place of origin (Ireland) found in the uses of the word home in the data from both Argentina and the USA, especially in letters sent to Ireland. In addition, the uses connected with Ireland showed a strong sense of emotion and homesickness as displayed through their collocations. Next, the adverbial forms here and there in relation to how they interact with the word home are examined in the letters, where the latter usually refers to home. In the USA corpus there is a higher percentage of the uses of negative attitudes associated with here than was the case in the Argentinian letters, which show more positivity. The low number of occurrences in this emphatic deictic use of the word there prevented the authors from drawing any significant conclusions, but a further examination of this country and its relationship with home show positive associations in the Argentina corpus. Changes over time, aligning with changes in identity, are suggested in the conclusion to this chapter but require a more detailed examination of individual writers over time where this might be possible.

Overall, variety is the word that comes strongly to mind when I reflect on the contents of this volume. A variety of languages, contexts, approaches, methodologies, datasets, epistemologies, and time periods are represented across the chapters. For me, this gives the book a richness not always found in more narrowly focussed volumes and, in turn, it opens the inquisitive mind to alternative ways of thinking about the same phenomenon: Irish English. I found myself on familiar and therefore comforting and enjoyable journeys through explorations of contemporary corpora of Irish English. At the same time, I was also challenged by some of the more strongly focussed historical sociolinguistic accounts of artefacts such as manuscripts and literature, not so familiar to my own professional context, but strangely, equally enjoyable to read and contemplate through unfamiliar lenses. It is this challenge which for me creates a satisfaction beyond just the ubiquitous 'interesting', for which I thank the authors. It was equally satisfying to read accounts from many familiar professional faces in the guise of institutional colleagues, as well as former students and colleagues. This gives me huge pride in the significant place that Limerick is playing in the scholarship of Irish English and the promotion of corpus-based methodologies in all areas of applied linguistics research. There was one minor niggle I had from reading the very first chapters of this volume, and 
that was the very broad focus on identity as a concept (a niggle, by the way, carried over from my own research into identity in language teacher education contexts). All authors rightfully acknowledge the difficulties associated with defining and pinpointing this term, but none really address the problems that this may cause in encircling so many researchbased accounts around it as a core concept. The main one, of course, is that in its broadness, it can become meaningless and elusive as a research theme. There were times when I wondered how this volume could easily be differentiated from a general sociolinguistic account simply entitled 'Irish English' in terms of its chapter contents, and while most chapters did manager to anchor to the concept of identity quite well, there were a couple which I felt did not achieve this to the same degree. This is, however, a very minor point and it did not detract from the huge pleasure I got from reading each page. In fact, reducing the concept further may not be possible, or even desirable. It might actually have undermined efforts to attract so many diverse accounts, all of which add to the richness and variety which I found so pleasing. I highly recommend this volume to all those with an interest in linguistics, sociolinguistics, corpus-based methodologies, and Irish English, and congratulate the editors on bringing it to fruition.

\section{REFERENCES}

Clancy, Brian. 2016. Investigating Intimate Discourse: Exploring the Spoken Interaction of Families, Couples and Friends. London: Routledge.

Hickey, Raymond. 2004. A Sound Atlas of Irish English. Berlin: Mouton de Gruyter.

Hickey, Raymond. 2007. Irish English: Its History and Present-day Forms. Cambridge: Cambridge University Press.

Love, Robbie, Claire Dembry, Andrew Hardie, Vaclav Brezina and Tony McEnery. 2017. The Spoken BNC2014: Designing and building a corpus of everyday conversations. International Journal of Corpus Linguistics 22/3: 319-344.

McCafferty, Kevin and Carolina P. Amador-Moreno. In preparation. CORIECOR Corpus of Irish English Correspondence. Bergen and Cáceres: Department of Foreign Languages, University of Bergen and Department of English, University of Extremadura, Cáceres.

O’Sullivan, Joan. 2019. Corpus Linguistics and the Analysis of Sociolinguistic Change. London: Routledge.

Reviewed by

Fiona Farr

The Centre for Applied Languages

School of Modern Languages and Applied Linguistics

University of Limerick

V94 T9PX Ireland

e-mail: fiona.farr@ul.ie 